\title{
SCIENCE OF METALS THROUGH LENS OF MICROSCOPE
}

Belma Fakić, Adisa Burić, Edib Horoz

University of Zenica, Institute "Kemal Kapetanović" of Zenica, Bosnia-Herzegovina

Email: belma.fakic@ikk.unze.ba, adisa.buric@ikk.unze.ba, edib.horoz@ikk.unze.ba

\begin{abstract}
:
Man atempts to know and see what is not visible with the naked eye goes back to the far past. By the combination of concave and convex lenses, in the 16th century, Dutchman Janssen made the first ever-increasing instrument. Robert Hooke was first used to illuminate objects using artificial light and gave a first description of plant cells still afar 1665. Henry Clifton Sorby, in the 1960s, was the first to apply a microscope in metal testing. Today, microscopes are used daily for the testing purity of metals and alloys, the presence of nonmetallic inclusions, the microstructural phase present in the alloys as a result of various forms of heat treatment. This paper gives an overview of the possibilities of light microscopes in the testing of metal materials.
\end{abstract}

Keywords: light microscope, metalic materials, steel, microstrukture 


\section{INTRODUCTION}

The material science explores metallic and non-metallic materials. Metallurgy is part of material science, separated as a special science, because of the extraordinary importance of metal in everyday life. Metal materials have a significant role in the economic development of the state and the world in general. The most widely used in the modern world are iron, carbon, chromium, nickel, molybdenum, steel and iron alloys. By studying the basic properties of metal and alloys, connection between chemical composition, microstructure and the principle of the change in their structure and properties is concerned with the physical metallurgy.

\section{METALLOGRAPHY}

As an independent science Physical metallurgy was started in the XIX century, initially called "Metalography". The term "Physical Metallurgy" (Germ. Physikalische Metallurgie, Russ. Металловедение) was introduced in Germany in the 20s of the 20th century, where it was proposed to preserve the term "Metallography" (Germ. Metallografie, Russ. Металлография) only for science about the macro and microstructure of metals and alloys. In many countries Physical Metallurgy is still referred to as Metallography [1].

Metallography means metal and graphs - the description of metals is basically a science of the structure of metals and alloys, and studies the principles of structure formation and examines the macrostructure and microstructure of metal, either by observing the naked eye, at small increases either by light (optical) or electronic microscope. In addition, X-ray diffraction microscopy (X-ray structure analysis) is also used for the study of microstructure. Metallography also studies the changes of mechanical, electrical, magnetic, thermal and other physical properties of metals depending on the change in its structure. Structural examination is necessary to find the "structure - property" connection and to establish the principle of structure formation to predict the properties of new alloys.

\subsection{First testing of metal structure}

The first study of the metal surface macrostructure, by etching, without additional optical aids, historically, was carried out by Reomir (1683-1757). He used different types of reagent to distinguish different type of steels. 
By etching in reagents, in 1774, Rinman recognized the damask steel - a steel for making a sword (a type of sword was forged in Damascus; and in the Balkans in Prizren and Sarajevo until 1878).

The Russian scientist P.P. Anosov (1799 - 1851) first applied a special metallographic microscope, with work in reflected light on specially prepared sample surfaces, for studying the structure of steel and its changes after forging and heat treatment, and established the existence of a connection between the structure and properties of steel [1].

\subsection{First examination of metal structure under microscope}

Henry Clifton Sorby, in 1863 in England. Was the first person who tested polished and crumpled metal samples under the microscope. H. C. Sorby was a geologist, a petrograph, and a minerologist. His samples were Swedish wrought iron and wrought iron armour plate, and blister steel $[2,3]$. Representation of the microstructure of steel observed by Sorby at the 9x increase is given in Figure 1. This macrograph shows distinct grain boundaries.

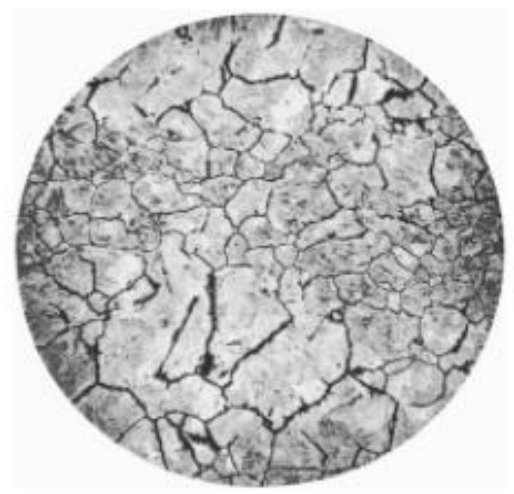

Figure 1: The first macrograph of blister steel,

Etched in very dilute nitric acid, 9 x [2,3]

A few years later, A. Martens (1878.) made the first metallographic samples and recorded the structures of steel and iron under a larger magnification in Germany.

Then, F. Osmond in France set up significant basics of metal science, especially on steel quenching. W. C. Roberts Austen made the first diagram of iron-carbon system in England at the end of the 19th century. The American H. N. Howe has introduced the names of microconstituents: ferrite, cementite, pearlite, hardenite, and Osmond names martensite, trustite and austenite [2]. 


\section{MICROSCOPE}

The meaning of the word microscope is obtained from the Greek words - mikros $=$ small and skopein $=$ see. The principle of complex microscope as an instrument was developed by the German manufacturer of glasses Zacharias Jansen since 1590. The inventor of the microscope is considered Anthony Van Leewenhoek, who first observed microscopic life in a little of water. Although the microscope used more than 200 years for various tests, the first time for metal testing was used by H.C. Sorby in the second half of the 19 th century [3]. The application of a microscope in the investigation of the metal with later application compared to the beginning of the application of the optical microscope in biology is obvious, since the metal microscopy requires a careful preparation of the samples surface, and in addition, the metals are untransparent and require observation in rejected light.

\subsection{Human eye}

The human eye observes the wavelength of 360 to $780 \mathrm{~nm}$, which corresponds to the interval of color from violet to dark red. It is maximally susceptible to the green light wavelength of $560 \mathrm{~nm}$. Therefore, green filters are often used in optical microscopes to obtain monochromatic images.

The ability to distinguish two separate points is called resolution (power of discernment). Two points lying next to each other can still be seen as separate when their spacing, according to Abe, is:

$$
d=\lambda / 2 n \sin \alpha
$$

where $\lambda$ represents the wavelength of light with which the pattern is lightened; $\mathrm{n}$ is the refractive index between the eye and the object (for air $\mathrm{n}=1$ ); angle $\alpha$ represents a angular aperture [2]. For the human eye it is $\sin \alpha \approx 0.02$. When using green light $(\lambda=560 \mathrm{~nm})$ in air ( $\mathrm{n}=1$ ) it is obtained that the resolving power of human eye is $\mathrm{d} \approx 0.02 \mathrm{~mm}$. Accordingly, the naked eye can differentiate the dimensions of a few tenth parts of millimeter [1]. It should be kept in mind that the resolving power of the human eye varies considerably [4].

\subsection{Light (optical) metallographic microscope}

Light (optical) microscope, in which the light reflected from the surface of the sample is used, is called a metallographic microscope. There are two types of metallographic microscopes: upright and inverted. On the upright microscope, the sample is placed below lens, while the inverted microscope sample is set upside down the lens. 
Several important features of light microscope are: lenses (objectives), eyepieces (oculars), light source, and camera.

\section{POSSIBILITIES OF LIGHT (OPTICAL) MICROSCOPE}

A major factor in metal testing with an light (optical) microscope is the preparation of the sample surface. There are few steps in preparation of samples [5]:

- cutting,

- $\quad$ mounting (if it is necessary),

- $\quad$ grinding - SiC grinding paper, grid: 120, 240, 480, 600, 1000

- $\quad$ polishing - using different clothes and diamond suspension, gradation 9, 6, 3 and $1 \mu \mathrm{m}$.

The aim is get mirror surface of sample.

Light (optical) microscope has few capabilities:

- observation in bright field,

- $\quad$ observation in dark field,

- polarization light,

- $\quad$ Differential interference contrast (DIC).

\subsection{Different views through ocular microscope}

Light (optical) microscope is used for:

- determination of contamination of non-metallic inclusions;

- determination type, size and distribution of graphite;

- microstructure of alloys after different heat treatment;

- $\quad$ determination size and form of grain;

- $\quad$ measure of microcracks, pores, cavities;

- $\quad$ measurement of thickness layer.

Different micrographs getting on light (optical) microscope OLYMPUS PMG3 which is located in Metallographic laboratory of Institute "Kemal Kapetanović" of Zenica.

The same micrograph of low carbon steel, using different filters is shown at figure 2. 


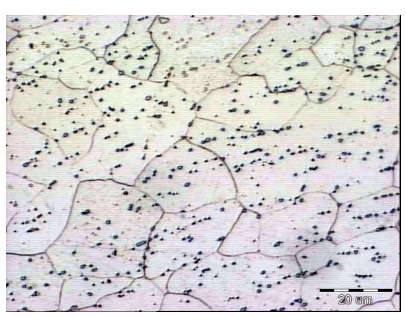

filter 0

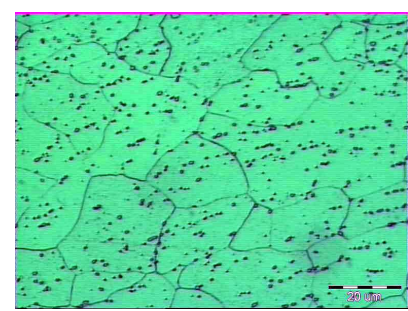

filter IF 550

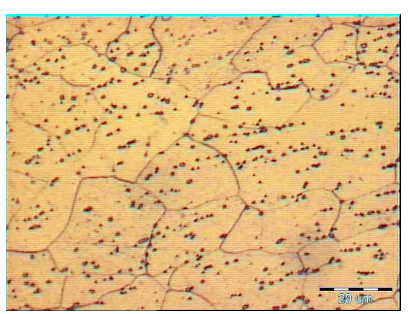

filter 0560

Figure 2. Different filter

Based on amount of ferrite and pearlite in steel, the content of carbon can be determined, what is shown at figure 3.

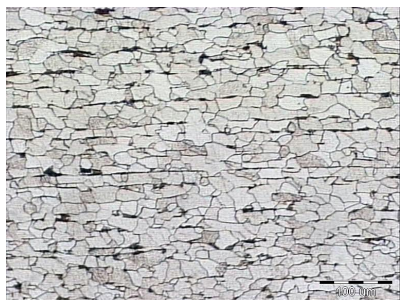

steel $(0,04 \% C)$

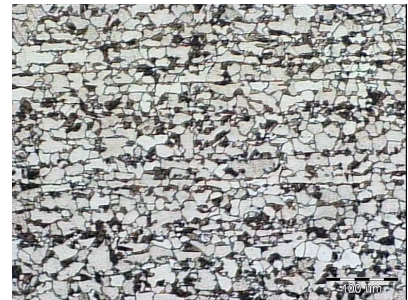

steel $(\mathbf{0 , 3 \%})$

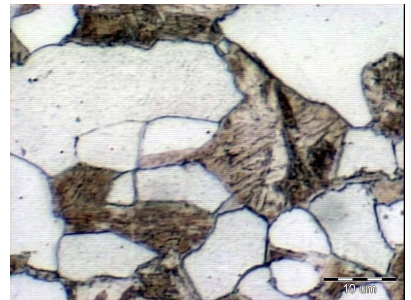

detail of pearlite

Figure 3. Microstructure with different amount of carbon (NITAL)

Non-metallic inclusion contamination is shown at figure 4.

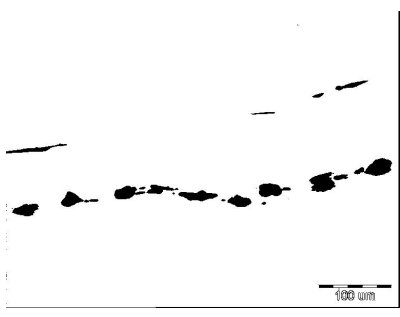

aluminates

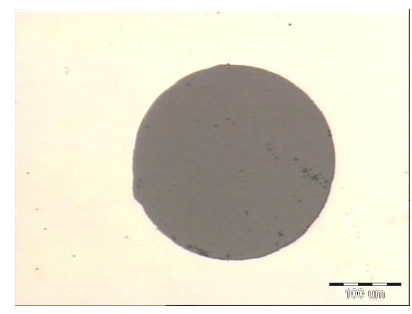

oxide

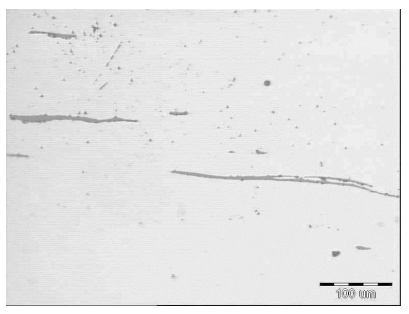

sulfide

Figure 4. Non-metallic inclusions, unetched

Microstructure of graphite, their different type, distribution and size are given at figure 5.

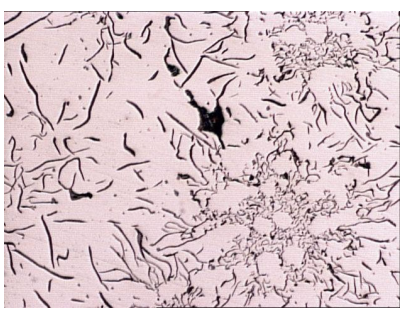

dendritic type

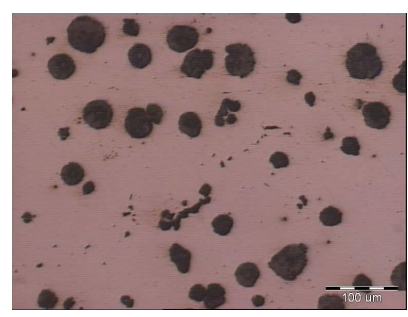

nodular type

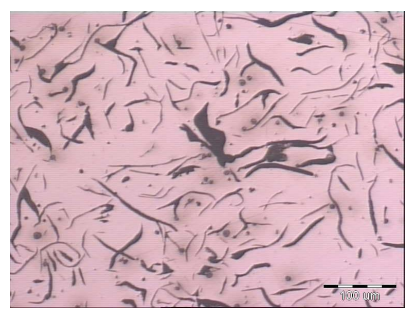

lamelar type 


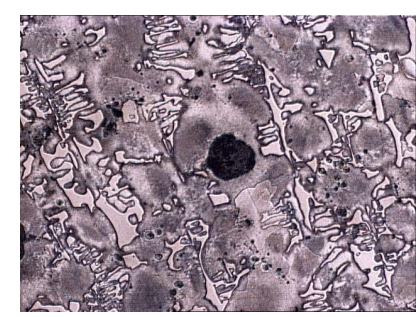

pearlite with cementite

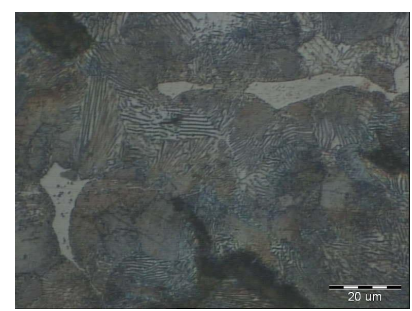

pearlite and phosphide eutectic

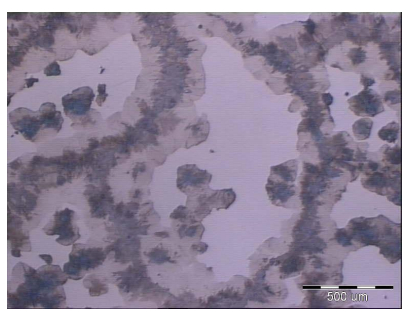

ferrite around nodulas and very fine pearlite

Figure 5. Graphite (first line - unetched, second line - etched in NITAL)

Microstructure of carbon steel C60, after different heat treatment (normalization, quenching and tempering) are given at figure 6.

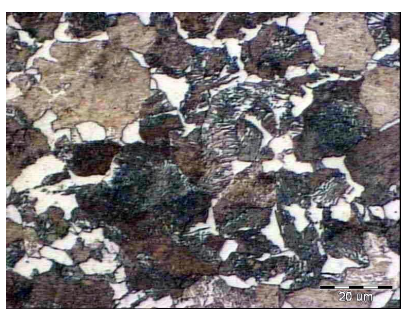

normalized pearlite and ferrite

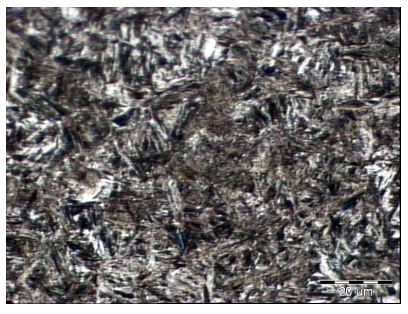

quenched in water martensite

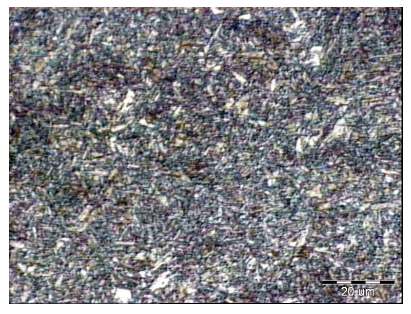

quenched and tempered tempered martensite

Figure 6. Microstructure of steel $\mathrm{C60}$ after different heat treatment (NITAL)

Different imperfections in weld joints of steel and pores in Zn alloy are shown at figure 7.

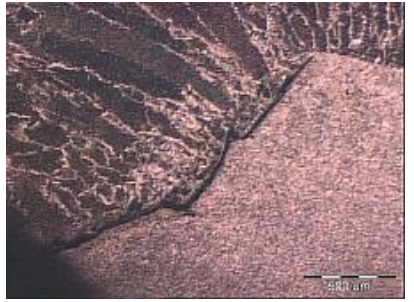

structural steel microcrack (ADLER)

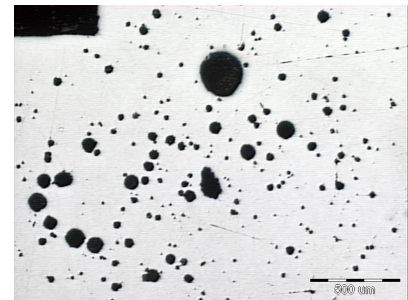

Zn alloy micropores (unetched)

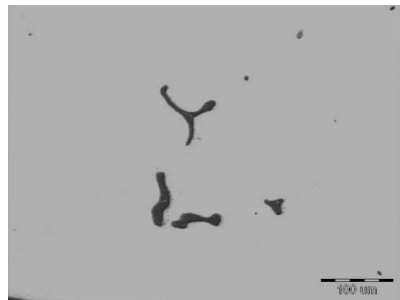

wrought steel porosity at grain boundaries

Figure 7. Microcracks, pores, porosity

Metallic material with different chemical composition has different form of grain. Grain size of stainless steel, steel 100Cr6 and brass are given at figure 8 .

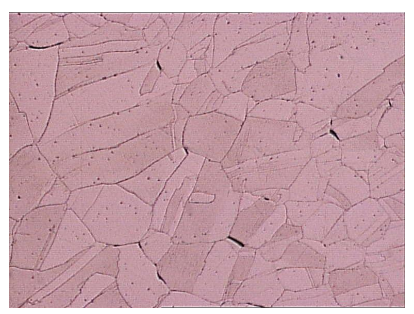

stainless steel

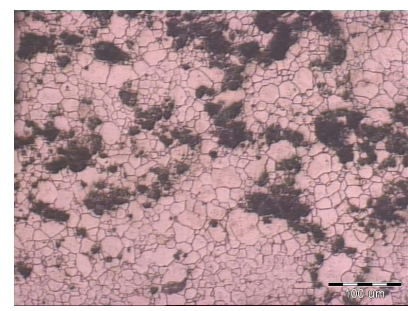

bearing steel $100 \mathrm{Cr} 6$

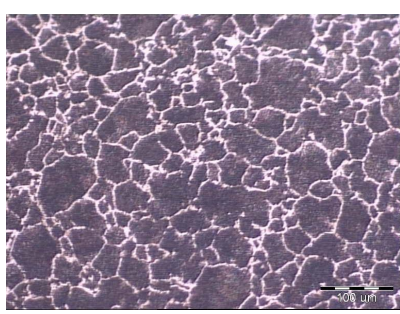

steel 17CrNiMo6 


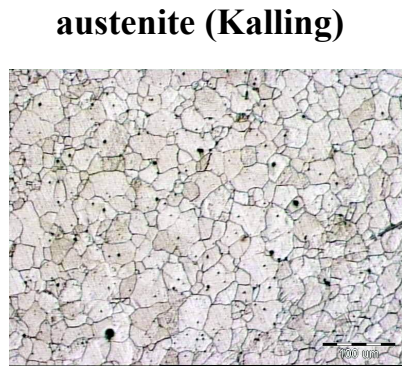

low carbon steel grain size in bright field

(NITAL)

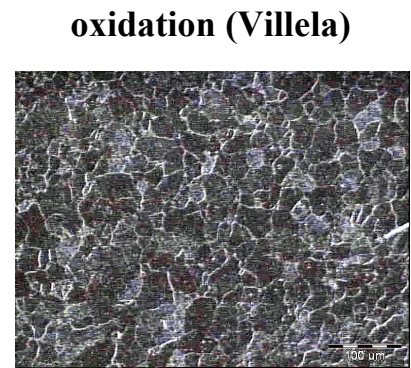

low carbon steel grain size in dark field

(NITAL)
McQuaid-Ehn (NITAL)

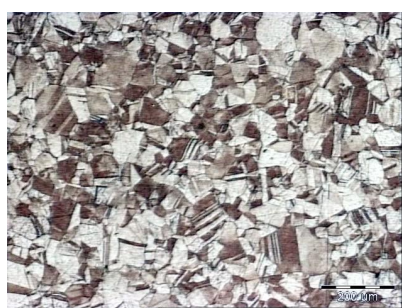

alloy of CuZn

grain size of brass

(FeCl3)

Figure 8. Size and form of grain

Different types and thickness of layers can be seen at surface of metallic materials. Figure 9 represents $\mathrm{Zn}$ and paint layer, decarburization and oxide layer.

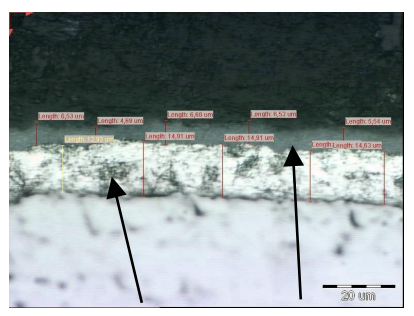

layer of $\mathrm{Zn}$ and paint (unetched)

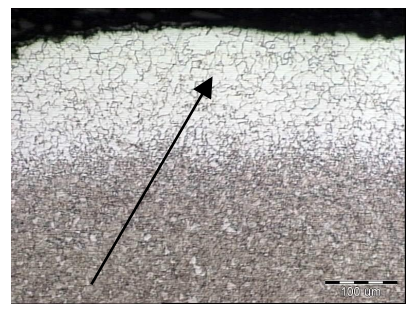

decarburization layer (NITAL)

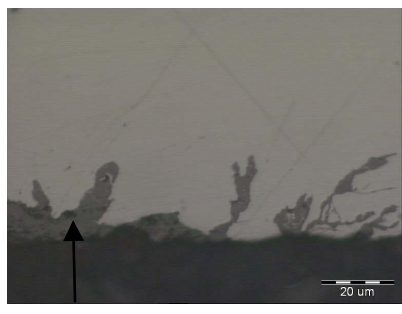

oxide layer, penetration (unetched)

Figure 9. Thickness layer

\section{CONCLUSION}

Metallography is part of physical metallurgy and it is irreplaceable instrument for research of metal and their alloys. Through the lens of light microscope can be seen all what is good in metal and that what is bad. Can be seen what we did in previous steps of production metallography shows us did we use correct temperature and cooling rate during heat treatment. Metallography is eyes and soul of science of metal and their alloys.

\section{REFERENCES}

[1] D. Marković, Fizička metalurgija 1, Univerzitet u Beogradu, Tehnički fakultet u Boru, 2013.

[2] H. Šuman, Metalografija, TMF, Beograd, 1989. 
[3] B.L. Bramfitt, Metallographer's guide, Practices and Procedures for Irons and Steels, ASM International, 2002.

[4] George F. Vander Voort, Metallography Principles and Practice, ASM Inernational, Fourth printing, June 2007

[5] ASTM E 3 -11 - Standard Guide for Preparation of Metallographic Specimens 